\title{
THE IMPACT OF HUMAN ACTIVITIES, NATURAL FACTORS AND CLIMATE TIME-LAG EFFECTS OVER 33 YEARS IN THE HEIHE RIVER BASIN, CHINA
}

\author{
GAO, N. N. ${ }^{1,2^{*}}-$ LI, F. ${ }^{2}-$ ZENG, H. ${ }^{1}-$ ZHENG, Y. R. ${ }^{3^{*}}$ \\ ${ }^{I}$ School of Urban Planning and Design, Peking University Shenzhen Graduate School, University \\ Town, Nanshan District, Shenzhen, Guangdong 518055, China \\ (phone: +86-186-1156-1826) \\ ${ }^{2}$ Shenzhen Institute of Building Research Co., Ltd., No. 29 Mei'ao 3rd Road, Futian District, \\ Shenzhen, Guangdong 518049, China \\ (phone: +86-185-1166-5630)
}

${ }^{3}$ Key Laboratory of Resource Plants, West China Subalpine Botanical Garden, Institute of Botany, Chinese Academy of Sciences, No. 20 Nanxin Village, Xiangshan, Beijing 100093, China

(phone: +86-135-5232-2091)

*Corresponding authors

e-mail/phone: bnugaonannan@163.com/+86-186-1156-1826; zhengyr@ibcas.ac.cn/+86-106283-6508

The two corresponding authors contributed equally to this work

(Received $2^{\text {nd }}$ Sep 2020; accepted $19^{\text {th }}$ Jan 2021)

\begin{abstract}
Vegetation is a key factor adapting to and mitigating climate change. The quantitative analysis of vegetation dynamics including climate and human activities is necessary to take appropriate actions to adapt to climate change and optimize vegetation distribution to mitigate it. This article integrates the relationship between climate, soil, socioeconomic factors and vegetation change using redundancy analysis (RDA) and partial redundancy analysis (pRDA): which also considers the time-lag effect of climate change. The correlation between vegetation and dynamics of the three periods at land-use and vegetation group levels in the 14 counties in Heihe River basin (HRB) of China was revealed. Results showed that the most important driving factor was groundwater depth and mean annual temperature with 15-year lag times. More variation of vegetation change was determined at land-use level (54.7\%) than that at vegetation group level $(42.0 \%)$ : Climate change factors explained more variations than human activities both at vegetation group and land-use level, so did the time-lag effect. Land use planning not is only necessary in urban area but also in rural area in HRB. To increase resilience of agriculture, we suggest appropriate grazing management strategy. Meanwhile time-lag effects are quite important for better evaluating vegetation dynamics under climate change.

Keywords: vegetation dynamics, climate change, climate adapting, mitigating climate risk, agriculture resilience
\end{abstract}

\section{Introduction}

Global warming will happen faster than we think, the time for rapid adaptation has arrived (Xu et al., 2018). Vegetation such as forest and agriculture play a key role in mitigating and adapting to climate change. Restoring natural forests is the best ways to remove atmospheric carbon (Lewis, 2019). We should make adaptive management strategies for agriculture which is vulnerable to climate change (Havstad et al., 2018). How to adjust or protect vegetation distribution in an effective way is a suspended problem because important human activities and natural factors vary from place to place. To solve the problem, it's necessary to find out major factors that caused changes in 
vegetation distribution at research site, which may be human activities, climate or other natural factors such as soil.

For climate fundamentally controls the distribution of ecosystems, species ranges, and process rates (Grimm et al., 2013), ecological systems are being altered by climate change throughout the world (Lawler et al., 2010). Meanwhile, 75\% of the area of Earth's icefree terrestrial biomes is affected by humans (Ellis and Ramankutty, 2008), and currently in many parts of the world, human activities are the main forces shaping land-use and ecosystem changes (Foley et al., 2005; Serra et al., 2008). Further, the extent of humaninduced land-cover change is increasing dramatically, which threatens biodiversity globally (Watson et al., 2014). Adaptation to climate change is getting more and more attention, Therefore, the impact of multiple stressors on vegetation has become one of the most pressing questions in ecology and biodiversity conservation (Sirami et al., 2017).

Quantifying vegetation change relationship with human activities and climate change is necessary to make suggestion to take action to mitigate or adapt to climate change. Vegetation changes can be triggered by climatic factors and human activities, separately or together, which influence vegetation on regional and global scales (Linderman et al., 2006; Wu et al., 2015). However, most studies on vegetation dynamics have only focused on the effects of climatic change (Nemani et al., 2003; Woodward and Lomas, 2004), despite repeated calls for better integration of multiple drivers (Didham et al., 2007; Mantyka-pringle et al., 2012; Oliver and Morecroft, 2014). In the absence of integrative multi-driver approaches, limited understanding of how interactions among drivers affect observed changes will likely hamper reliable projections and relevant conservation recommendations (Titeux et al., 2016). Thus, understanding vegetation dynamics and its response to both climatic change and human activities is important.

Ordination is an effective method to solve complicated ecological multivariate analysis. In quantitative analysis of vegetation distribution causal factors, many simulation models and statistical analysis methods have been used, such as the Sheffield Dynamic Global Vegetation Model (Woodward and Lomas, 2004), biome-specific production efficiency model (Nemani et al., 2003), Principal Component Analysis and Ordination. During Ordination Analysis, Forward Selection via the Monte Carlo permutation test is typically used to select suitably representative factors that explain most vegetation variations (Lepš and Šmilauer, 2003).

This article integrates multiple drivers such as climatic, soil and the socioeconomic factors, to accurately simulate spatiotemporal changes of vegetation in the Heihe River basin (HRB) over a recent 33 years (1980-2013) and to distinguish the effects of various causal factors on vegetation dynamics at land-use and vegetation group levels. The main objectives of this study were: 1) quantitative analysis of vegetation dynamics and responses to climatic change and human activities; 2) comparison of the difference of these correlations at land-use and vegetation group levels; and 3) the time-lag effects of temperature and precipitation on the variation of vegetation distribution. The results will be useful to promote protection of the ecological environment and making agricultural adaptive management strategies in the study region.

\section{Materials and methods}

\section{Site description}

The Heihe River basin is the second largest inland river basin of China. It is a relatively independent and diversified geographic unit in the northwestern part of the 
country at the intersection of the northeast margin of the Tibetan Plateau and southern slopes of the Gobi-Altay Mountains, and covers an area of $143,000 \mathrm{~km}^{2}$, which includes 14 counties (Table 1; Fig. 1). The basin is an important grain producing region because of its relatively abundant water resources, with a mean annual runoff of $3.73 \times 109 \mathrm{~m}^{3}$ at high points in the basin. Precipitation and evaporation have strong spatiotemporal heterogeneity under the influence of geographic factors and atmospheric circulations in this basin.

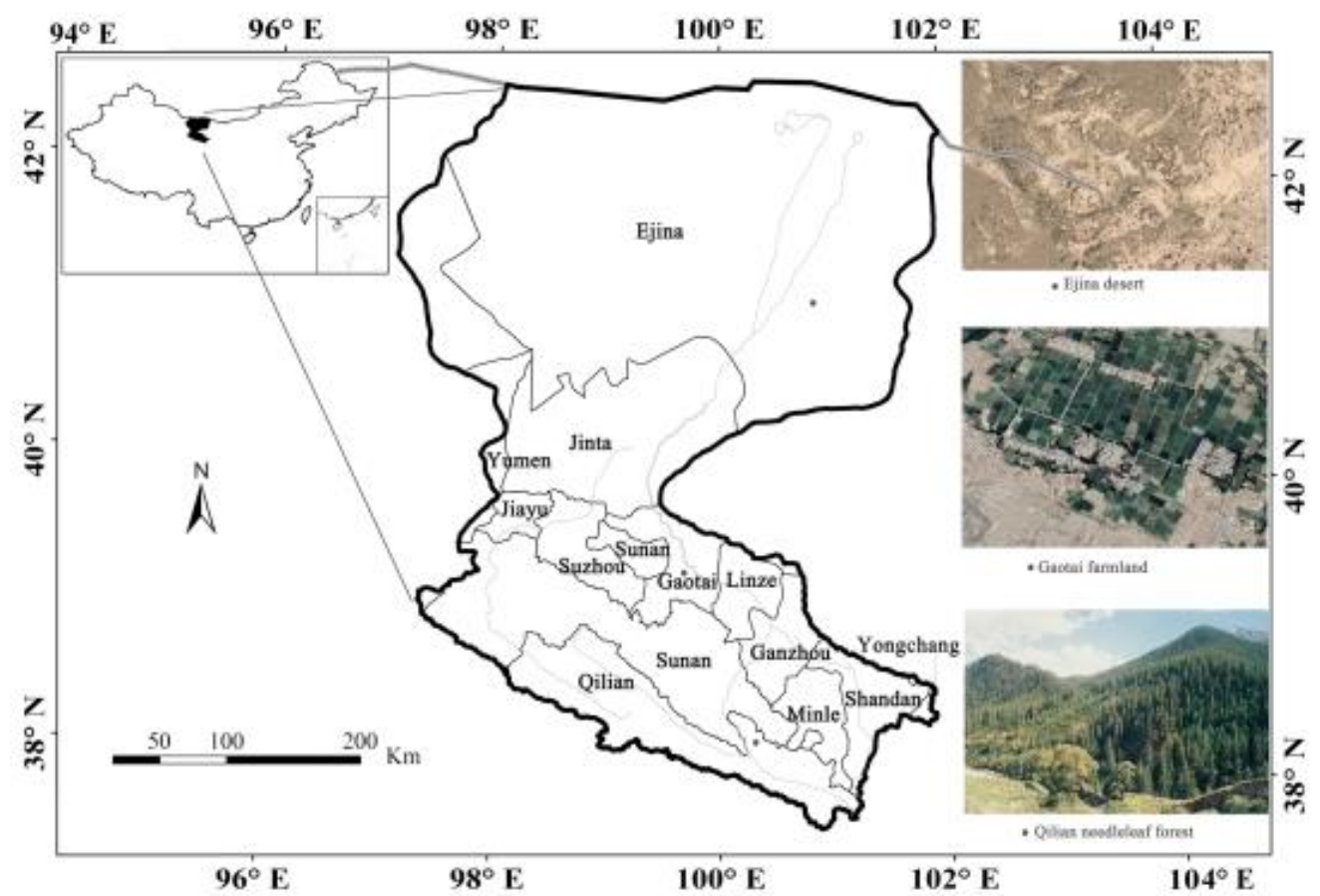

Figure 1. Location of Heihe River basin (HRB) and counties in the basin

The HRB has three major divisions, namely, the upper, middle and lower reaches, which are marked by various natural conditions and socioeconomic development states. The upper reaches, with elevations from 2180 to $5547 \mathrm{~m}$, have a humid cold climate. This is the main runoff portion of the watershed and the main land cover is pasture. The middle reaches are between the Qilian and Beishan mountains, at elevations 1289 to $3920 \mathrm{~m}$. This is the main water consumption zone, where most of the land has been reclaimed for oasis agriculture. It accounts for $95 \%$ of the $8471 \mathrm{~km}^{2}$ cultivated land, $91 \%$ of the 26 billion population, and more than $80 \%$ of the GDP of the 16.5 billiondollar GDP of the entire Basin (Cheng et al., 2014). The area has a continental arid temperate climate with mean annual precipitation from 100 to $250 \mathrm{~mm}$. The lower reaches form the tail-end zone, mainly occupied by the barren Gobi Desert, with a huge evaporative capacity and very fragile ecological environment. Elevation in this area is about $1000 \mathrm{~m}$. Mean annual precipitation is less than $50 \mathrm{~mm}$.

The HRB is severely affected by both climate change and human activities (Cheng et al., 2014; $\mathrm{Wu}, 2011)$. Change of the hydrologic processes of HRB has substantially modified the local environment over recent decades, including environmental degradation, salinization and desertification (Luo et al., 2016). Further, around 2000, the local government started an ecological project, returning cultivated land to grassland 
and diverting water to the lower reach to recover a disappeared lake in the HRB. Therefore, the basin may be an ideal area to understand the effects of climate and human activities on vegetation distribution.

Table 1. Basic information of climate, social economy and vegetation of counties in the HRB

\begin{tabular}{|c|c|c|c|c|c|c|c|}
\hline County & \begin{tabular}{|c|}
$\begin{array}{c}\text { Altitude } \\
(\mathbf{m})\end{array}$ \\
\end{tabular} & \begin{tabular}{|c|}
$\begin{array}{c}\text { Temperature } \\
\left({ }^{\circ} \mathbf{C}\right)\end{array}$ \\
\end{tabular} & $\begin{array}{c}\text { Precipitation } \\
(\mathbf{m m})\end{array}$ & \begin{tabular}{|c|} 
GDP \\
(million RMB) \\
\end{tabular} & \begin{tabular}{|c|} 
Population \\
(capita)
\end{tabular} & Main land use & $\begin{array}{c}\text { Main vegetation } \\
\text { group }\end{array}$ \\
\hline Ejina & 1142 & 7 & 46 & 2024 & 19846 & Barren land & Desert \\
\hline Jinta & 1313 & 8 & 48 & 2862 & 144442 & Barren land & Desert \\
\hline Subei & 1703 & 5 & 49 & 1800 & 12449 & Barren land & Desert \\
\hline Jiayu & 1768 & 6 & 65 & 12147 & 200557 & Barren land & Desert \\
\hline Yumen & 1544 & 7 & 51 & 8364 & 174039 & Barren land & Desert \\
\hline Suzhou & 1566 & 7 & 77 & 8448 & 367793 & Barren land, farmland & $\begin{array}{l}\text { Desert, cultural } \\
\text { vegetation }\end{array}$ \\
\hline Gaotai & 1488 & 8 & 84 & 2380 & 158077 & Barren land, farmland & $\begin{array}{l}\text { Desert, cultural } \\
\text { vegetation }\end{array}$ \\
\hline Linze & 1494 & 8 & 91 & 2201 & 147168 & Barren land, farmland & $\begin{array}{l}\text { Desert, cultural } \\
\text { vegetation }\end{array}$ \\
\hline Ganzhou & 1692 & 7 & 149 & 7536 & 492928 & Barren land, farmland & $\begin{array}{l}\text { Desert, cultural } \\
\text { vegetation }\end{array}$ \\
\hline Shandan & 2533 & 4 & 325 & 2263 & 200353 & Desert, steppe, farmland & $\begin{array}{l}\text { Desert, steppe, } \\
\text { cultural vegetation }\end{array}$ \\
\hline Minle & 2423 & 4 & 372 & 1810 & 232632 & $\begin{array}{l}\text { Barren land, farmland, } \\
\text { pasture }\end{array}$ & $\begin{array}{c}\text { Desert, cultural } \\
\text { vegetation, meadow, } \\
\text { steppe, alpine }\end{array}$ \\
\hline Yongchang & 2346 & 4 & 242 & 3274 & 253248 & Barren land, pasture & Desert, steppe \\
\hline Sunan & 3214 & -1 & 290 & 1256 & 36237 & Pasture, barren land & $\begin{array}{c}\text { Steppe, alpine, } \\
\text { meadow }\end{array}$ \\
\hline Qilian & 3831 & -4 & 491 & 822 & 48050 & $\begin{array}{l}\text { Pasture, barren land } \\
\text { shrub }\end{array}$ & $\begin{array}{l}\text { Meadow, alpine, } \\
\text { shrub }\end{array}$ \\
\hline
\end{tabular}

Altitude $(\mathrm{m})$, temperature $\left({ }^{\circ} \mathrm{C}\right)$, and precipitation $(\mathrm{mm})$ in this table presented are mean data of the individual counties

\section{Data and preprocessing}

Temporal and spatial scale affect analysis results of the relationship between vegetation and driving factors (Sirami et al., 2017). Considering that China began to compile development statistical yearbooks where socioeconomic data was from in 2000, and sequenced climate and soil data of HRB were updated from 1980 to 2013, the study period was 1980 to 2013 when climate time lag effect when studied.

\section{Satellite imagery data and pre-processing}

The satellite imageries were relatively cloud-free $(<5 \%$ cloud cover) Landsat Thematic Mapper (TM), Enhanced Thematic Mapper Plus (ETM+) and Operational Land Imager (OLI) image data from 2000, 2007 and 2013 in July during growing season, with a 30-meter spatial resolution. All images were downloaded from the Geospatial Data Cloud (available at http://www.gscloud.cn/) following the same criteria, i.e., cloud cover, quality and date of acquisition in the late dry season. Eleven Landsat scenes were selected to cover the study area. All scenes for each year were used after radiometric calibration and fast atmospheric correction processing in ENVI 5.3.1 software. Google Earth image and map were used as ancillary data. 


\section{Satellite imagery data classification}

Several kinds of data were analyzed by discriminant analyses using image random forest (RF) classification (Cutler et al., 2007) in which (1) Landsat data (2000, Landsat ETM+, seven data channels; 2007, Landsat TM, seven data channels; 2013, Landsat 8 OLI, nine data channels); (2) geographic data (elevation, slope, aspect and terrain ruggedness index, four data channels); (3) spectral index data (NDVI, difference vegetation index, enhanced vegetation index, water index, and normalized difference built-up index, five data channels) were included. RFs are decision tree ensembles for the classification or regression of categorical and continuous data (Breiman, 2001). the RF classifier is a very useful analytical tool and is considered very desirable for multisource classification of remote sensing and geographic data (Gislason et al., 2006).

Finally, Land-use and Vegetation group types were got. Land-use types included forest, shrub, water, farmland, settlements, pasture and barren land (Fig. 2; Table 2). Vegetation group types were desert, meadow, needleleaf forest, broadleaf forest, alpine vegetation, shrub, steppe, cultural vegetation and land without vegetation. Classification system was according to Editorial Committee of Vegetation Map of China (CAS, 2007).

Table 2. Characteristics of land use and vegetation group in the HRB

\begin{tabular}{c|c|c|c|c|c|c}
\hline \multicolumn{2}{c|}{ Types } & $\mathbf{2 0 0 0}$ & $\mathbf{2 0 0 7}$ & $\mathbf{2 0 1 3}$ & $\begin{array}{c}\text { Area change } \\
\text { (ha)* }\end{array}$ & $\begin{array}{c}\text { Area change } \\
(\mathbf{\%})^{*}\end{array}$ \\
\hline \multirow{6}{*}{ Land use } & Forest & 167,589 & 170,684 & 189,018 & 21,429 & 12.79 \\
& Shrub & 393,729 & 428,016 & 533,305 & 139,576 & 35.45 \\
& Water & 160,674 & 104,011 & 115,403 & $-45,271$ & -28.18 \\
& Farmland & 595,033 & 683,750 & 847,137 & 252,104 & 42.37 \\
& Settlements & 35,003 & 48,722 & 63,348 & 28,345 & 80.98 \\
& Pasture & $2,340,302$ & $2,344,829$ & $2,056,240$ & $-284,062$ & -12.14 \\
& Barren land & $10,585,586$ & $10,497,903$ & $10,473,466$ & $-112,120$ & -1.06 \\
\hline \multirow{5}{*}{ Vegetation } & Desert & $10,193,292$ & $10,026,082$ & $9,892,044$ & $-301,248$ & -2.96 \\
group & Meadow & $1,312,043$ & $1,242,152$ & $1,100,090$ & $-211,953$ & -16.15 \\
& Needleleaf forest & 132,224 & 138,867 & 158,057 & 25,833 & 19.54 \\
& Broadleaf forest & 35,365 & 31,817 & 30,961 & $-4,405$ & -12.45 \\
& Alpine vegetation & 392,294 & 471,821 & 581,422 & 189,128 & 48.21 \\
& Shrub & 393,729 & 428,016 & 533,305 & 139,576 & 35.45 \\
& Steppe & $1,028,259$ & $1,102,677$ & 956,150 & $-72,109$ & -7.01 \\
& Cultural vegetation & 595,033 & 683,750 & 847,137 & 252,104 & 42.37 \\
& Land without vegetation & 195,677 & 152,734 & 178,751 & $-16,926$ & -8.65 \\
\hline
\end{tabular}

*The time interval is $2000-2013$

\section{Climate, soil and human activity data}

Log-transformation was used to normalize the response variable (vegetation data) and explanatory variable (climate, soil, economic and social factors) to ensure that the response variable data were not less than zero and the explanatory variables were comparable and at least contain one positive number. It was calculated by Equation 1.

$$
X=\log _{10}\left(X_{i} \times a+1\right) \times b
$$


Here $\mathrm{X} i$ is original value of variable $\mathrm{X} i, \mathrm{X}$ is log-transformed value of $\mathrm{X} i$, a and $\mathrm{b}$ are constants to make sure all $\mathrm{X}$ are comparable in the same axis.
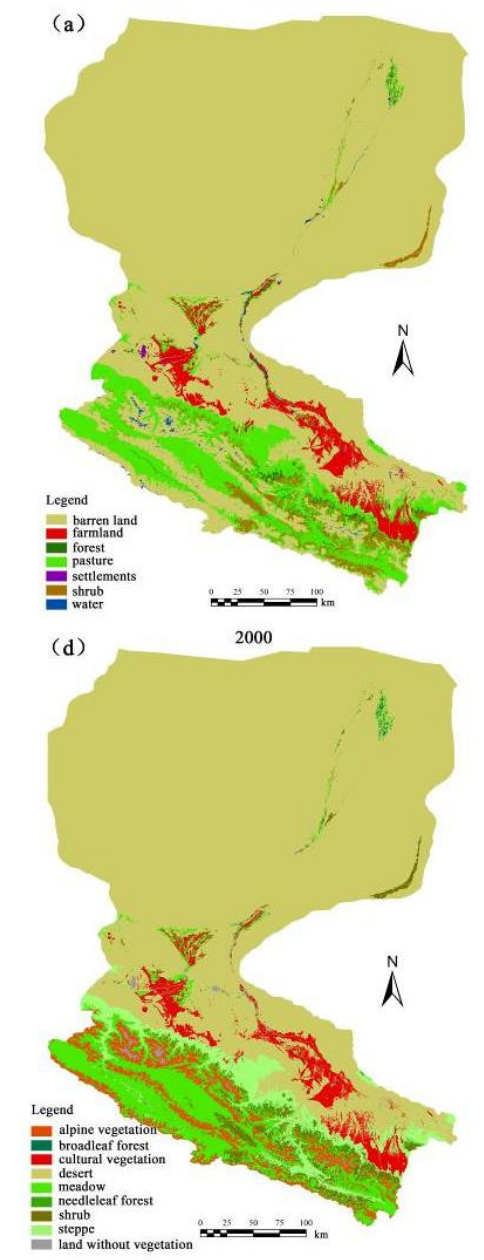
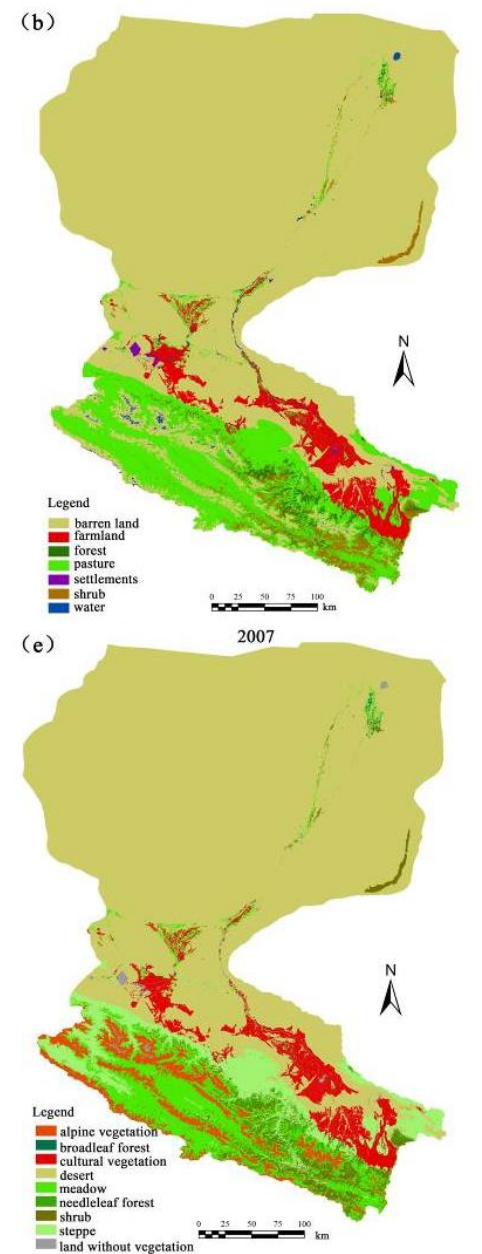
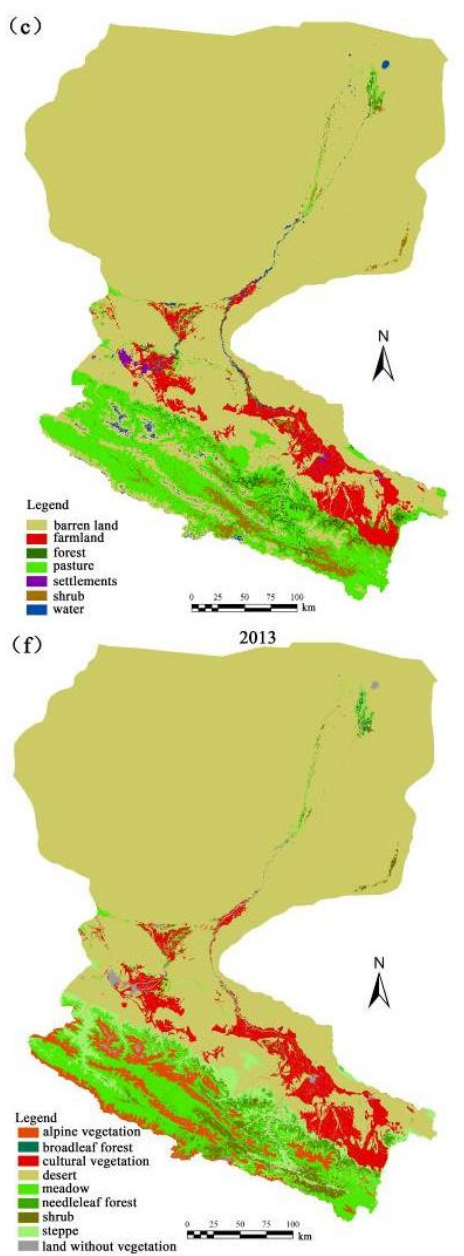

Figure 2. Classification of land use $(a, b, c)$ and vegetation group $(d, e, f)$ in the HRB

Climate and soil data, such as mean annual temperature (T), evapotranspiration (EVAP), soil moisture measured at $100 \mathrm{~cm}$ from surface (SM100), groundwater depth (ZWT), and other factors were considered. The explanatory variables were analyzed and showed in figures below after removing the collinear factors (collinearity exists if VIF > 10) (Borthwick et al., 2020). These data were provided by the Data Cloud of the Chinese Academy of Sciences (Fig. 3).

Time-lag effect of climatic factors was also included as considering that vegetation distribution reaction to climate change may last several years (Figs. 3, 4 and 5). Timelag series was set as follow, 0 year (abbreviation 0yr, the same as following, 2000's), 1 year (1yr, 1999's), 2 years (2yr, 1998's), 3 years (3yr, 1997's), 4 years (4yr, 1996's), 5 years (5yr, 1995's), 10 years (10yr, 1990's), 15 years (15yr, 1985's), and 20 years (20yr, 1980's). To match the vegetation and land use data of 2000, 2007 and 2013, the time-lag year was set as 0yr (2000, 2007, 2013), 1yr (1999, 2006, 2012), 2yr (1998, 2005, 2011), 3yr (1997, 2004, 2010), 4yr (1996, 2003, 2009), 5yr (1995, 2002, 2008), 10yr (1990, 1997, 2003), 15yr (1985, 1992, 1998) and 20yr (1980, 1987, 2003), respectively. 


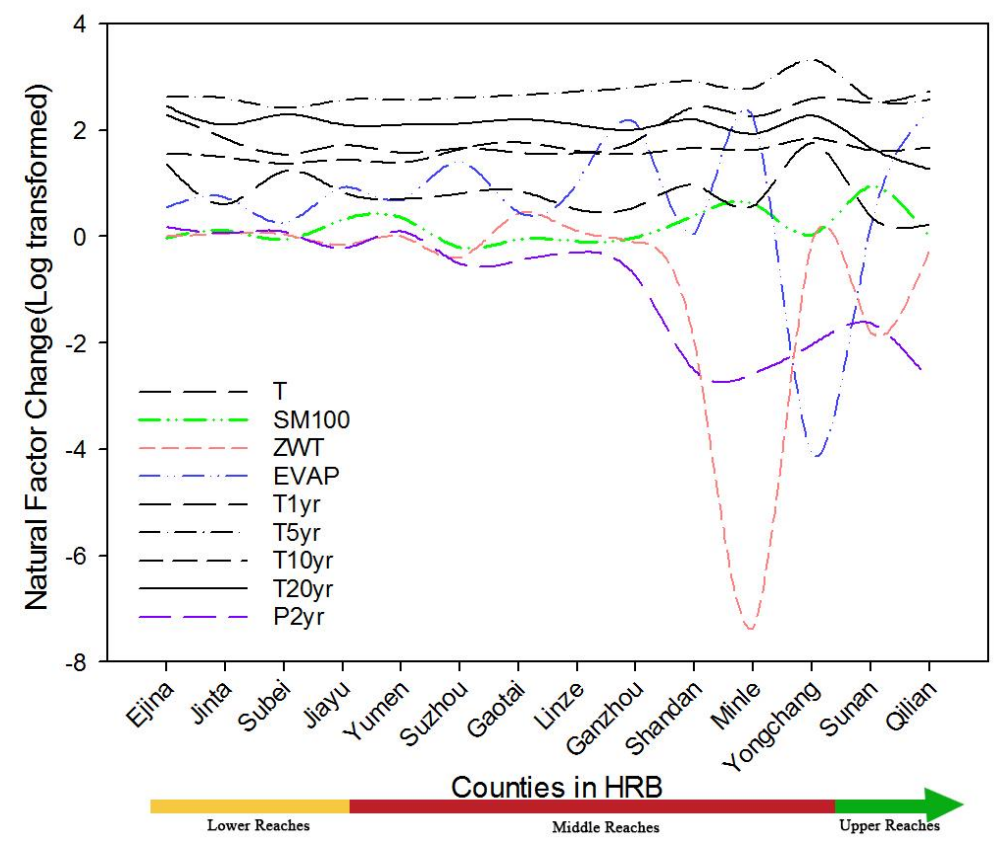

Figure 3. Natural factors change during 2000-2013 by counties in the HRB. The abbreviations are mean annual temperature (T), evapotranspiration (EVAP), oil moisture measured at $100 \mathrm{~cm}$ from surface (SM100), groundwater depth (ZWT). The time-lag year was set as 0yr (2000, 2007, 2013), $1 y r(1999,2006,2012), 2 y r(1998,2005,2011), 3 y r(1997,2004,2010), 4 y r$ (1996, 2003, 2009), 5yr (1995, 2002, 2008), 10yr (1990, 1997, 2003), 15yr (1985, 1992, 1998) and 20yr (1980, 1987, 2003), respectively

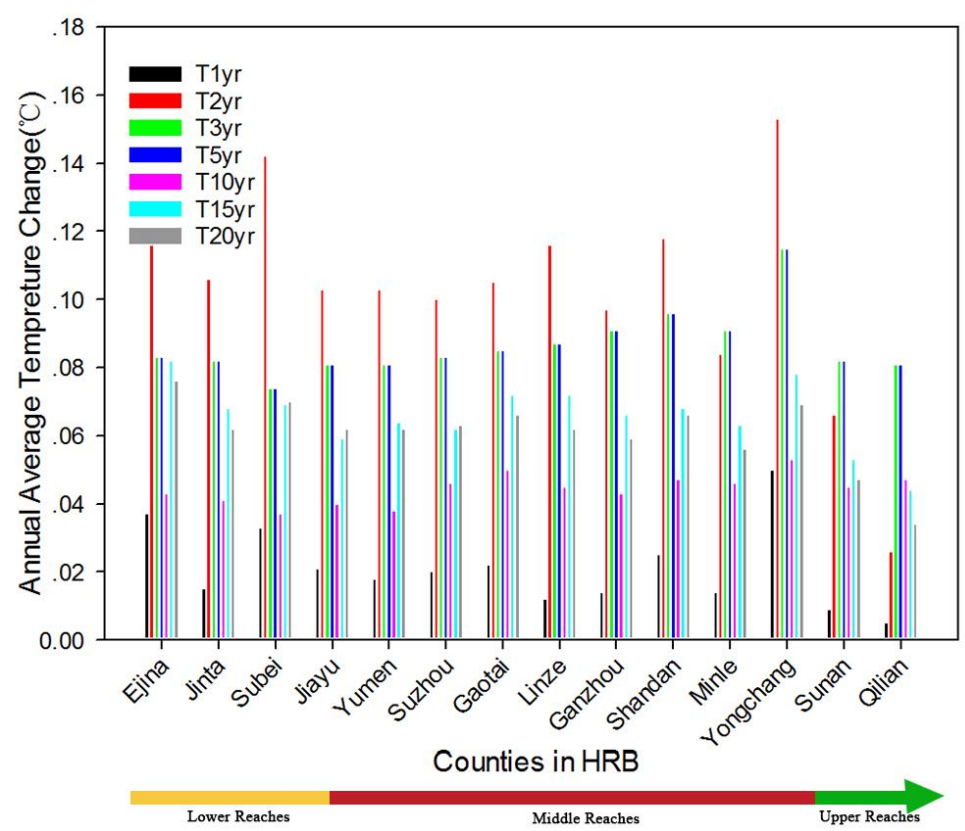

Figure 4. Annual Average Temperature change of various lag time by counties in 1980-2013. The abbreviations are temperature $(T)$ of the time-lag year. The time-lag year was set as Oyr (2000, 2007, 2013), $1 y r(1999,2006,2012), 2 y r(1998,2005,2011), 3 y r(1997,2004,2010)$, $4 y r(1996,2003,2009), 5 y r(1995,2002,2008), 10 y r(1990,1997,2003), 15 y r(1985,1992$, 1998) and 20yr (1980, 1987, 2003), respectively 


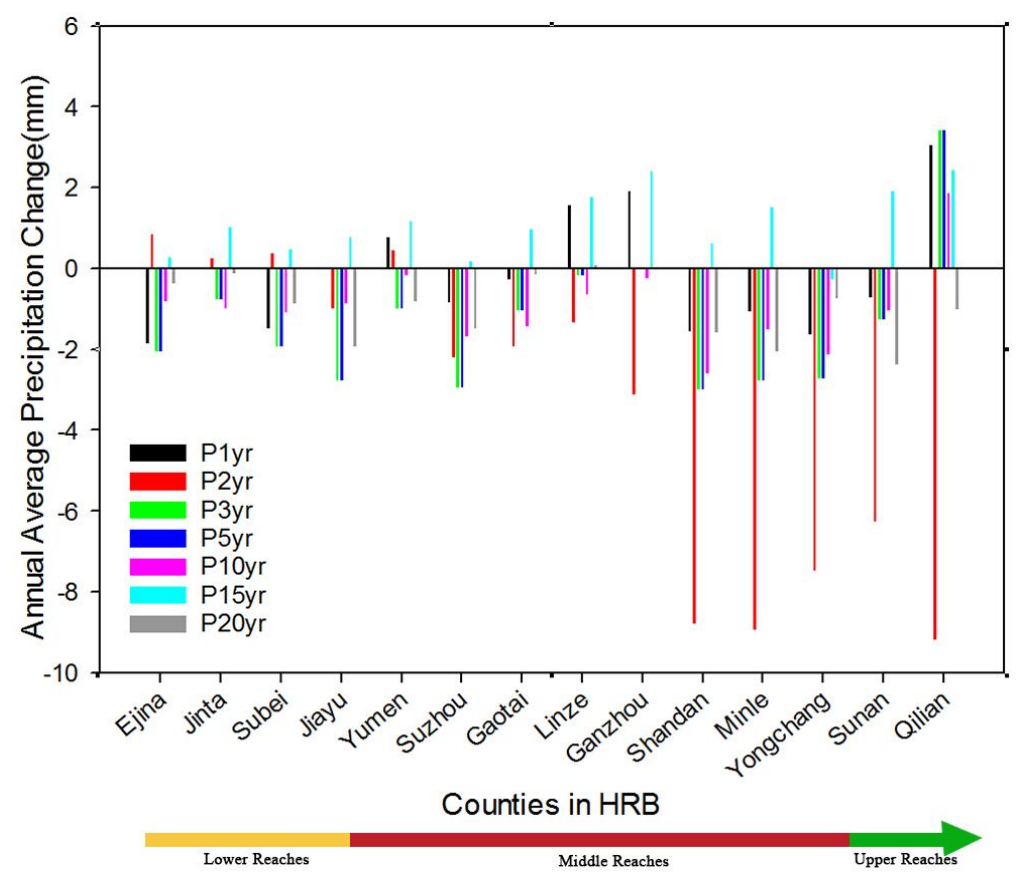

Figure 5. Annual average precipitation change of various lag time by counties in 1980-2013. The abbreviations are precipitation $(P)$ of the time-lag year. The time-lag year was set as 0yr (2000, 2007, 2013), 1yr (1999, 2006, 2012), 2yr (1998, 2005, 2011), 3yr (1997, 2004, 2010), 4yr (1996, 2003, 2009), 5yr (1995, 2002, 2008), $10 y r(1990,1997,2003), 15 y r(1985,1992$, 1998) and 20yr (1980, 1987, 2003), respectively

Social and economic statistics data, such as agricultural GDP per capita (GVAP/AP), agricultural GDP per GDP (GVAP/GDP), agricultural GDP (GVAP), urban population (UP), pasturage density (PD), and other factors were considered. Only variables pass forward selection were showed in figures below. They were derived from the statistical yearbook, the government bulletin of counties in the HRB (Fig. 6).

Policy impact was considered qualitatively. An ecological water diversion project diverting water to lower reach in the Heihe River basin (Cheng et al., 2014) was implemented in 2000, the project of returning farmland to forest and grass in the upstream area of the basin was implemented in 1999 and an afforestation project was implemented in the 1990s. However, there was a difference in the timing and enforcement of policies in each county.

\section{Analysis of vegetation distribution change}

Vegetation classification levels have effect on vegetation distribution (Gao et al., 2017). We analyzed the relationship between vegetation distribution and drivers at landuse and vegetation group level, respectively. Land cover is predominantly humanoriented and is more likely to be reasonably planned for farmland and residential areas. The vegetation group represents plant biomes, which is conducive to the protection of species, scientific division of nature reserves, and development and utilization of ecological resources. The vegetation dynamic index K (Wang and Bao, 1999) was used to quantitatively describe the vegetation distribution change rate in a certain period in the research area, was calculated by Equation 2. 


$$
K=\left[\frac{(U 2-U 1)}{U 1}\right] \times\left(\frac{1}{T}\right) \times 100 \%
$$

Here, $\mathrm{K}$ is the dynamic index of land-use (vegetation group) type in the research period. $\mathrm{U} 1$ is the area of land type $\mathrm{i}$ at the beginning time and $\mathrm{U} 2$ is the area of land cover (or vegetation group) type $i$ at the final time. $T$ is the research period, with the year as its basic unit. $\mathrm{K}$ is the annual change rate of land-use type $\mathrm{i}$. This model can be used to analyze and compare the change rate of different land-use types in the research area, with $|\mathrm{K}| \leq 0.5 \%$ (the absolute of $\mathrm{K}$ was not less than $0.5 \%$ ) indicating small change, $0.5 \% \leq|\mathrm{K}| \leq 1.5 \%$ moderate change, $1.5 \% \leq|\mathrm{K}| \leq 2.5 \%$ large change, and $|\mathrm{K}| \geq 2.5 \%$ great change.

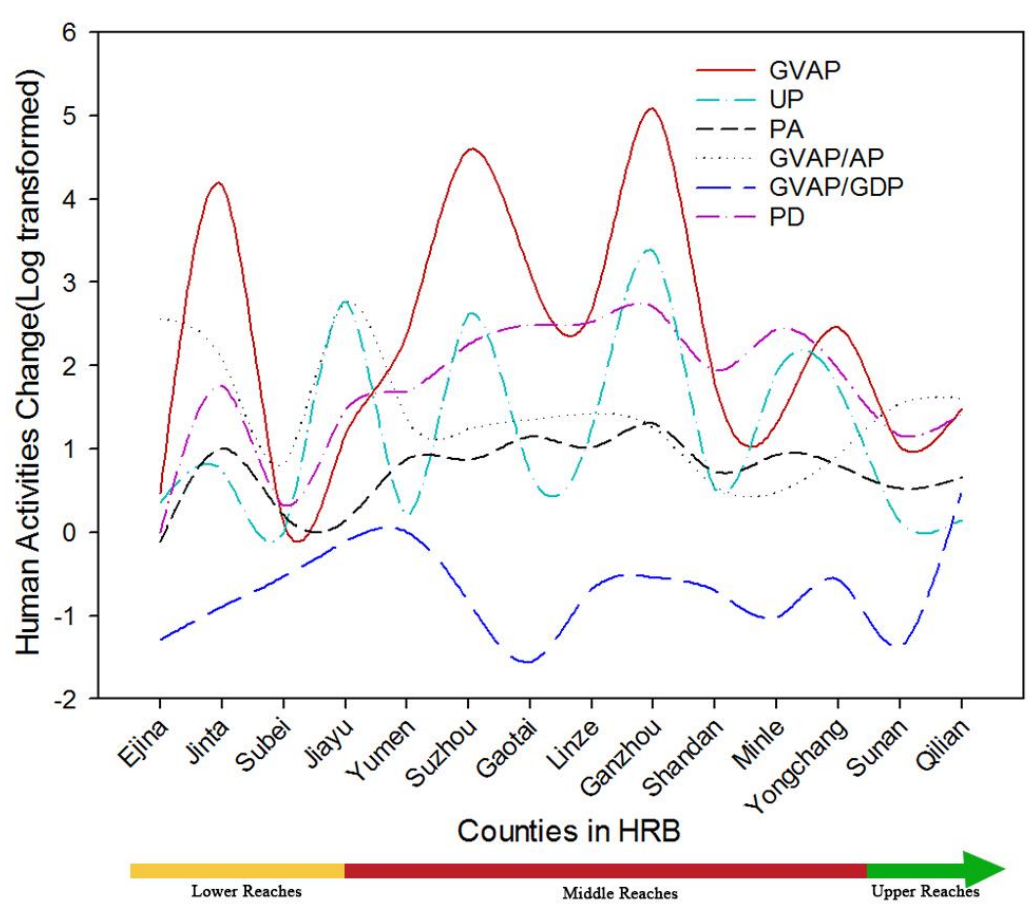

Figure 6. Social and economic factor change during 2000-2013 by counties in the HRB. The abbreviations are agricultural GDP per capita (GVAP/AP), agricultural GDP per GDP $(G V A P / G D P)$, agricultural GDP (GVAP), urban population (UP), pasturage (PA), pasturage density $(P D)$

\section{Correlation analysis}

Correlation between land cover, vegetation group and causal factors data were analyzed by constrained ordination via the Canoco for Windows program (version 4.5) (ter Braak and Smilauer, 2002). Dynamic index data of 2000-2007, 2007-2013 and 2000-2013 of the 14 counties in the Heihe River basin were used as species data.

Detrended correspondence analysis (DCA) was conducted for response variables to detect the length of the species gradient, to decide whether to use unimodal or linear methods. After that, RDA was used because the lengths of gradients were smaller than 3 in the study. The Monte Carlo permutation test was used to test significance of the relationship with explanatory variables (Lepš and Šmilauer, 2003). "Automatic selection" and "Monte Carlo permutation tests" were used in the forward selection of 
environmental variables, removing explanatory variables with the smallest explanatory value ( $p$-value $>0.05$ ) and leaving the retained explanatory variable with $p$-value $\leq 0.5$ and variance inflation factor $<10$. Forward selection of variables (Montgomery et al., 2012) was used to determine the relative importance of environmental variables and variance explained by them.

The results of the RDA were plotted as two-dimensional graphs using CanoDraw (Version 4.5). The continuous environmental variables were plotted as arrows originating from the center of the graph. Although RDA analysis can identify the main effects on land-use or vegetation group change, it is difficult to distinguish the overall contribution of human and climate factors to variance of such change, so a partial RDA method was also used to distinguish the effect of human activity and climate change.

\section{Results}

\section{Climate, soil and human activity change}

As shown in Figure 3, natural factors do not fluctuate much in the downstream and midstream areas near the downstream of HRB, while ZWT, P2yr, EVAP, and SM100 change drastically in the upstream and near upstream areas.

As shown in Figure 4, temperature of HRB had increased significantly. T2yr in the middle and lower reaches is significantly higher than that of other lag time. There is not a strong correlation between changes in vegetation distribution and unusual dramatic temperature changes in a year (as T2yr), but long-term temperature changes profoundly affect vegetation changes (Fig. 3).

As shown in Figures 3 and 5, the effect of precipitation change on vegetation pattern is not as great as that of temperature change. Precipitation changes a lot in the last 20 years, and the decline is the main trend. Especially P2yr, the decline is obviously greater than $6 \mathrm{~mm} / y e a r$. Unlike temperature, vegetation distribution change only has relationship with dramatic precipitation change of 2-year lag time.

As shown in Figure 6, human activities are more dramatic than the natural factors. Considering the proportion of GDP, the agricultural GDP proportion decreased, while the industrial and service GDP proportion increased in all counties. PD change is higher in the middle reaches than in the upper and lower reaches. But other factors have no special trend of different regions.

\section{Land cover and vegetation change}

Main land cover type in HRB was barren land, which accounted for $>72 \%$ of the entire basin (72.84\% in 2000 and $73.35 \%$ in 2013). The second largest type was pasture, accounting for $15.64 \%$ and $14.40 \%$ in 2000 and 2013, respectively, followed by farmland. Barren land, shrub, farmland, settlements (including residential, transportation, and industrial and other) increased, and forest, water and pasture decreased from 2000 to 2013. Pasture and farmland areas showed the largest changes by area of $-284,062$ and $+252,103$ ha, respectively. Change of settlements and farmlands showed the largest changes by percentage of $80.98 \%$ and $42.37 \%$, as their Dynamic index K was 6.23 and 3.26, respectively (Table 2).

Main type in HR of vegetation group was desert, which made up $>69 \%$ of the entire basin (71.39\% in 2000 and $69.28 \%$ in 2013). The second largest type was meadow, 
accounting for $9.19 \%$ and $7.70 \%$ in 2000 and 2013, respectively, followed by steppe and cultural vegetation. Cultural vegetation, alpine vegetation, shrub, and needleleaf forest increased, while desert, meadow, steppe, land without vegetation, and broadleaf forest decreased from 2000 to 2013. Alpine vegetation and cultural vegetation showed large changes by area of -301247.93 and +252103.67 ha, respectively. Changes of alpine and cultural vegetation showed the largest changes by percentage of $48.21 \%$ and $42.37 \%$, as their K values were 3.71 and 3.26 , respectively (Table 2).

\section{Land cover and vegetation change, and causal factors}

At the land-use level, the results show that the Monte Carlo test of the first and all canonical axes had significant correlation $(\mathrm{p}<0.01)$. The sum of all canonical eigenvalues was 0.547 and total variance was 1.00 . The explained variance contributions of the first and first two axes reached $36.7 \%$ and $78.0 \%$, respectively (Table 3). Forward selection of variables indicated that change of groundwater depth accounted for $9 \%$ of the variance $(\mathrm{p}=0.002)$, greater than that of any other variable. It was positively related to change of barren land and pasture. The change of mean annual temperature explained $8 \%(\mathrm{p}=0.004)$ of the total variance (Table 4$)$ and was positively related to change of settlements. Change of pasturage explained $6 \%(\mathrm{p}=0.038)$ of the total variance and was positively related to change of farmland, and negatively related to change of shrub and forest. Change of mean annual temperature with a time-lag of one year $(\mathrm{T} 1 \mathrm{y})$ explained 5\% ( $\mathrm{p}=0.044)$ of the total variance. Evaporation change was negatively related to barren, pasture change. Precipitation change was positively related to pasture change and negatively related to change of barren land (Fig. 7).

Table 3. Summary of RDA ordination

\begin{tabular}{|c|c|c|c|c|c|}
\hline Level & Summary & Axes 1 & Axes 2 & Axes 3 & Axes 4 \\
\hline \multirow{7}{*}{ Land use } & Eigenvalues & 0.201 & 0.171 & 0.095 & 0.044 \\
\hline & Land use-environment correlations & 0.845 & 0.860 & 0.722 & 0.528 \\
\hline & \begin{tabular}{|c|} 
Cumulative percentage variance of \\
land use-environment relation
\end{tabular} & 36.7 & 78.0 & 84.5 & 93.4 \\
\hline & Sum of all eigenvalues & \multicolumn{4}{|c|}{1.000} \\
\hline & Sum of all canonical eigenvalues & \multicolumn{4}{|c|}{0.547} \\
\hline & $\begin{array}{l}\text { Test of significance of first } \\
\text { canonical axis }\end{array}$ & \multicolumn{4}{|c|}{$P$-value $=0.002$} \\
\hline & $\begin{array}{c}\text { Test of significance of all } \\
\text { canonical axes }\end{array}$ & \multicolumn{4}{|c|}{$P$-value $=0.002$} \\
\hline \multirow{7}{*}{$\begin{array}{l}\text { Vegetation } \\
\text { group }\end{array}$} & Eigenvalues & 0.156 & 0.1122 & 0.062 & 0.029 \\
\hline & $\begin{array}{l}\text { Vegetation group-environment } \\
\text { correlations }\end{array}$ & 0.830 & 0.725 & 0.747 & 0.575 \\
\hline & \begin{tabular}{|c|}
$\begin{array}{c}\text { Cumulative percentage variance of } \\
\text { vegetation-environment relation }\end{array}$ \\
\end{tabular} & 37.18 & 66.17 & 80.92 & 87.77 \\
\hline & Sum of all eigenvalues & \multicolumn{4}{|c|}{1.000} \\
\hline & Sum of all canonical eigenvalues & \multicolumn{4}{|c|}{0.420} \\
\hline & $\begin{array}{l}\text { Test of significance of first } \\
\text { canonical axis }\end{array}$ & \multicolumn{4}{|c|}{$P$-value $=0.002$} \\
\hline & $\begin{array}{c}\text { Test of significance of all } \\
\text { canonical axes }\end{array}$ & \multicolumn{4}{|c|}{$P$-value $=0.002$} \\
\hline
\end{tabular}


Table 4. Explained variance of variables analyzed by redundancy analyses (China Ministry of Agriculture, 2015)

\begin{tabular}{|c|c|c|c|c|}
\hline Level & Category & Variables & Explained variance $(\%)$ & $P$-value \\
\hline \multirow{10}{*}{ Land use } & \multirow{6}{*}{$\begin{array}{l}\text { Climate } \\
\text { change }\end{array}$} & $\mathrm{T}$ & 8 & 0.004 \\
\hline & & $\mathrm{T}_{10 \mathrm{yr}}$ & 4 & 0.050 \\
\hline & & $\mathrm{T}_{1 \mathrm{yr}}$ & 5 & 0.044 \\
\hline & & EVAP & 4 & 0.048 \\
\hline & & SM100 & 5 & 0.040 \\
\hline & & ZWT & 9 & 0.002 \\
\hline & \multirow{4}{*}{ Human activity } & GVAP/GDP & 4 & 0.014 \\
\hline & & GVAP & 4 & 0.040 \\
\hline & & PD & 5 & 0.006 \\
\hline & & PA & 6 & 0.020 \\
\hline \multirow{8}{*}{$\begin{array}{l}\text { Vegetation } \\
\text { group }\end{array}$} & \multirow{5}{*}{$\begin{array}{l}\text { Climate } \\
\text { change }\end{array}$} & $\mathrm{T} 20 \mathrm{yr}$ & 11 & 0.002 \\
\hline & & T5yr & 7 & 0.005 \\
\hline & & EVAP & 5 & 0.024 \\
\hline & & $\mathrm{P} 2 \mathrm{yr}$ & 4 & 0.050 \\
\hline & & SM100 & 4 & 0.052 \\
\hline & \multirow{3}{*}{ Human activity } & UP & 4 & 0.048 \\
\hline & & GVAP/GDP & 4 & 0.050 \\
\hline & & GVAP/AP & 4 & 0.050 \\
\hline
\end{tabular}

Variables abbreviations: mean annual temperature $(\mathrm{T})$, mean annual temperature with a time-lag of one/ten years (T1yr/T5yr/...T20yr), mean annual precipitation with a time-lag of two years (P2yr), evapotranspiration (EVAP), soil moisture measured at $100 \mathrm{~cm}$ from surface (SM100), groundwater depth (ZWT) and agricultural GDP (GVAP), agricultural GDP per capita (GVAP/AP), agricultural GDP percentage (GVAP/GDP), agricultural population (AP), urban population (UP), Pasturage (PA), pasturage density (PD)

The results of partial RDA using human activity factors as the explanatory variable and climate change factors as covariates showed that correlation coefficients of the first and second axes of climate change factors and land use were 0.754 and 0.617 , respectively. The human activity factors with significant effect explained $26.3 \%$ of the variance of land-use change. From the results of partial RDA using climate change factors as the explanatory variable and human activity factors as covariates, the correlation coefficients of the first and second ordinal axes of climate change factors and land use were 0.831 and 0.697 , respectively, and $41.3 \%$ of the variation of land use was explained by the climate change factors with significant effect.

At vegetation group level, the results show that the Monte Carlo test of the first and all canonical axes had significant correlation $(\mathrm{p}<0.01)$. The sum of all canonical eigenvalues was 0.420 and total variance was 1.00 . The explained contributions of the first and first two axes reached $37.18 \%$ and $76.17 \%$, respectively. Forward selection of variables indicated that change of mean annual temperature of twenty years ago since the study year accounted for $11 \%$ of the variance $(p=0.002)$, greater than that of any other variables. That change was positively related to change of desert and broadleaf forest, but negatively related to needleleaf forest, alpine vegetation, steppe, shrub, meadow and land without vegetation. Change of mean annual temperature of twenty 
years ago since the study (T5yr) and evapotranspiration explained 7\% $(\mathrm{p}=0.005)$ and $5 \%(\mathrm{p}=0.024)$ of the total variance. T5yr was negatively related to change of cultural vegetation. Agricultural GDP percentage change has a negative relationship with change of cultural vegetation and land without vegetation (Fig. 8).

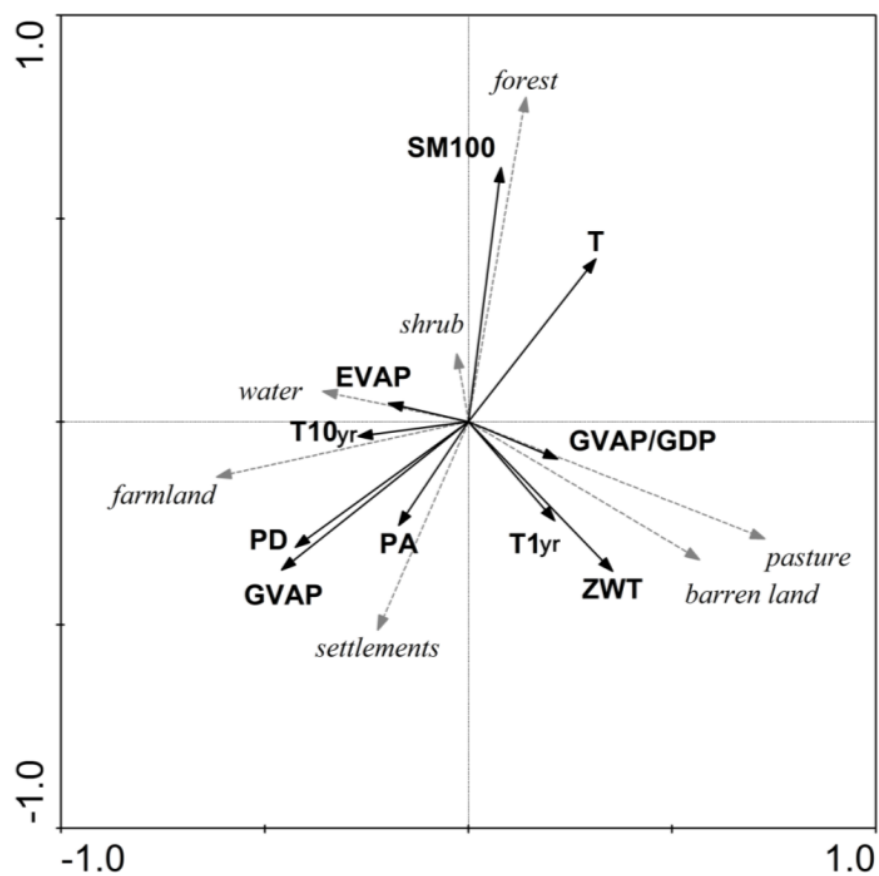

Figure 7. Redundancy analysis diagram in the HRB for land use types and driving factors.

Gray arrows represent land use types, black arrows represent driving factors. The abbreviations are mean annual temperature $(T)$, evapotranspiration (EVAP), oil moisture measured at $100 \mathrm{~cm}$ from surface (SM100), groundwater depth (ZWT), T1yr (mean annual temperature of 1999, 2006, 2012), T10yr (mean annual temperature of 1990, 1997, 2003), agricultural GDP per GDP (GVAP/GDP), agricultural GDP (GVAP), pasturage (PA), pasturage density $(P D)$, respectively

The results of partial RDA using human activity factors as explanatory variables and climate change factors as covariates show that correlation coefficients of the first and second axes of human activity factors and land use were 0.644 and 0.511 , respectively. Human activity factors with significant effect explained $17.7 \%$ of the variance of vegetation group change. The results of partial RDA using climate change factors as explanatory variables and human activity factors as covariates showed that correlation coefficients of the first and second ordinal axes of change in climate change factors and vegetation group were 0.816 and 0.726 , respectively. Moreover, $34.5 \%$ of the variation of vegetation group was explained by the climate change factors with significant effect.

\section{Discussion}

Previous studies have shown that spatiotemporal heterogeneity of vegetation growth and distribution is impacted by social and natural conditions (Jalut et al., 2009; Vincens et al., 2003). In this study, the influence of society and human beings was quantitatively expressed by population, GDP of agriculture, industry and service, and amount of 
livestock of each region. Through redundant analysis (RDA) and partial redundancy analysis (pRDA), we quantitatively analyze the synergistic effects of human and natural factors and their relative independent effects. The response of vegetation distribution to climatic variations varied among vegetation types. In various regions of $\mathrm{HRB}$, the economy developed rapidly and urbanization accelerated (Cheng et al., 2014). For regions that underwent intensive human landscape change, great effort is needed toward climate mitigation and adaptation (Pielke Sr et al., 2011). At land-use level, Land-use changes are strongly regionalized (Pielke Sr et al., 2011). Although settlement and croplands occupy a little of the total land area, $\mathrm{K}$ of them were the biggest. They are highly regionalized into concentrated landscape perturbations (Pielke Sr et al., 2011). It is suggested to do land use planning in the HRB not only in urban area but also in rural area.

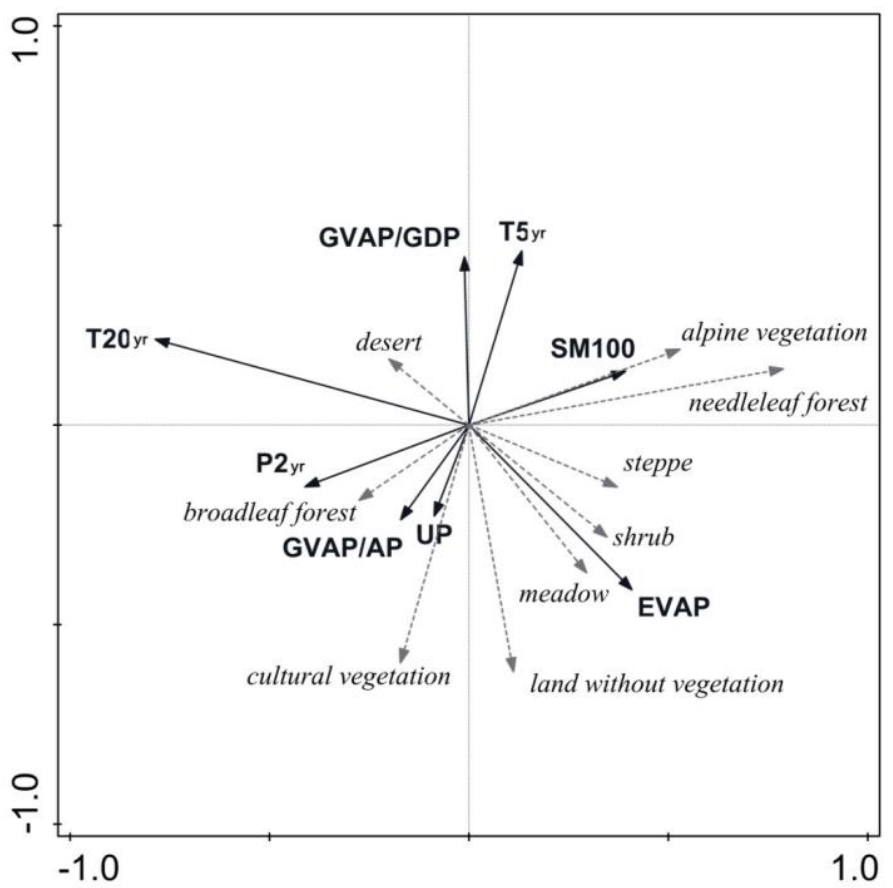

Figure 8. Redundancy analysis diagram in the Heihe River basin for vegetation groups and driving factors. Gray arrows represent vegetation group types, black arrows represent driving factors. The abbreviations are evapotranspiration (EVAP), oil moisture measured at $100 \mathrm{~cm}$ from surface (SM100), 2yr (mean annual precipitation of 1998, 2005, 2011), $5 y$ r (mean annual temperature of 1995, 2002, 2008), $20 y$ (mean annual temperature of 1980, 1987, 2003), agricultural GDP per capita (GVAP/AP), agricultural GDP per GDP (GVAP/GDP), urban population $(U P)$, respectively

The relationship between vegetation group and casual factors was weaker than that between land use and drivers. Climate change factors explained more at land-use level $(41.3 \%)$ than that at vegetation group level (34.5\%). Human activity factors explained less at vegetation group level $(17.7 \%)$ than at land-use level $(26.3 \%)$. The explanation of constrained ordination between response and explanatory variables at land-use level $(54.7 \%)$ was much stronger than that at vegetation group level $(42.0 \%)$. The vegetation responses to climate vary considerably with the diverse spatial patterns and the time-lag effects (Davis, 1989; Wu et al., 2015). 
In the mountainous upper reaches, climate change was the controlling factor This region is presently experiencing a century-long wet period (Qin et al., 2010). Because climate change has caused a transition from warm-dry to warm-wet conditions in northwestern China, rainfall might increase, but rising temperatures may weaken the influence of increased precipitation and runoff from the mountains (Shi, 2003). Although climate change will have a huge impact on vegetation groups and land use in the region, the influence of human activities factors cannot be ignored. Agricultural GDP percentage was an important human activities factor that affected changes of vegetation in this region.

Human activities have been dominant factor for vegetation change in the middle reaches. Increasing population and industrial development will augment greenhouse gas emissions, and continued emission of those gases will cause further warming and longlasting changes in all components of the climate system (IPCC, 2014). This situation may bring much more pressure on relatively fragile ecosystems that depend on water. Therefore, it is imperative to control population growth and improve industrial structure to restore ecosystem. However, the ecological project started by the local government in 2000 suggested that the direction of the human activity would be an open question, whether negatively or positively influences the vegetation structure.

Analyzing correlation between human activities and natural factors can help to understand human activity changing according to natural factors, and to mitigate climate change through adjusting human activities. At the two classification levels, most relevant implications for agriculture are due to changes in temperature (Fuhrer et al., 2014). At the level of land use, trend direction of PD, GVAP, and AP is opposite to T. The higher the temperature increment is, the higher agricultural GDP, agricultural population and pasturage density decrement are. Agriculture as a primary means by which the impacts of climate change are transmitted to the poor (Hertel and Rosch, 2010). At the level of vegetation type, T5yr is most closely related to human activities. The higher the T5yr rise, the more agriculture sector accounts for GDP increase, the more UP and GVAP/AP decrease. It is good for agriculture, for global warming not so harmful for all plants (Kolanowska, 2017). To increase inherently resilience of agriculture in the HRB, and the capacity to adapt and transform as needed to the climatic changes across this region, such as changed or improved crops, reduced stocking rates, proper grazing management practices, employing animal genetics suited to environments are suggested adaptive management strategies (Havstad et al., 2018).

It also provides a research method for the quantitative study of the effects of natural and human activities on vegetation distribution change. However, it should be noted that the research on the quantitative impact of social factors on vegetation distribution is still not accurate. This is because the acquisition of spatial data of social factors is sometimes difficult. But the contemporary long-time satellite remote sensing data provides an advanced way to monitor the vegetation dynamics in relation to climate variations at different spatiotemporal scales (Huete, 2016; Zhang et al., 2013). The good news is that in June 2018 China's Luojia01 night-time satellite officially started working and provided free night-time light imagery data. The data has a resolution of up to $120 \mathrm{~m}$ (Jiang et al., 2018; Zhang et al., 2019; Gao et al., 2019). There is a very significant positive correlation between night-time light imagery data and GDP (Doll et al., 2006; Wu et al., 2013), and the image can provide a good data base of spatial GDP data. It is also a feasible method for quantifying the influence of social factors in the future. 


\section{Conclusion}

Vegetation is a key factor adapting to and mitigating climate change. The main goal of the current study was to determine key vegetation dynamics including climate and human activities to better adapt to and mitigate climate change. This study showed that groundwater depth and mean annual temperature with 15-year lag times are the most important factors. It also found that land use planning is necessary not only for urban area but also for rural area in HRB to guide the direction of land-use change, and ultimately affect regional climate change. The research has also provided a research method for the quantitative study of the effects of natural and human activities on vegetation distribution change. Multiscale quantitative impact of social and natural factors on vegetation distribution are suggested with access to high accuracy data. Also examining the land cover changes would be beneficial divided by reaches level because of the different climatic conditions and vegetation.

Acknowledgements. This research was funded by the Study on the Synergetic Mechanism of Urban Energy Structure, Carbon Emission and Air Pollution, International Cooperation Projects of Shenzhen Science and Technology Innovation Committee, China grant number GJHZ20190822173805220; the National Key R\&D Program of China grant number 2017YFE0101700; the National Natural Science Foundation of China grant number 91425301.

\section{REFERENCES}

[1] Borthwick, R., de Flamingh, A., Hesselbarth, M. H. K., Parandhamanm, A., Wagner, H. H., Abdel Moniem, H. E. M. (2020): Alternative quantifications of landscape complementation to model gene flow in banded longhorn beetles [Typocerus v. velutinus (Olivier)]. - Frontiers in Genetics 11:307. DOI: 10.3389/fgene.2020.00307.

[2] Breiman, L. (2001): Random forests. - Machine Learning 45(1): 5-32.

[3] CAS (2007): The Vegetation Map of the People's Republic of China (VMC, 1:1,000,000). - http://www.nsii.org.cn/chinavegetaion.

[4] Cheng, G., Xiao, H., Feng, Q., Xiao, S., Zhao, W., Xu, Z., et al. (2014): Integrated study of the water-ecosystem-economy in the Heihe River Basin. - National Science Review 1(3): 413-428.

[5] Cutler, D. R., Edwards, T. C., Jr., Beard, K. H., Cutler, A., Hess, K. T., Gibson, J., Lawler, J. J. (2007): Random forests for classification in ecology. - Ecology 88: 27832792.

[6] Davis, M. B. (1989): Lags in vegetation response to greenhouse warming. - Climate Change 15(1-2): 75-82.

[7] Didham, R. K., Tylianakis, J. M., Gemmell, N. J., Rand, T. A., Ewers, R. M. (2007): Interactive effects of habitat modification and species invasion on native species decline. - Trends in Ecology \& Evolution 22(9): 489-496.

[8] Doll, C. N. H., Muller, J. P., Morley, J. G. J. (2006): Mapping regional economic activity from night-time light satellite imagery. - Ecological Economics 57(1): 75-92.

[9] Ellis, E. C., Ramankutty, N. (2008): Putting people in the map: anthropogenic biomes of the world. - Frontiers in Ecology and The Environment 6(8): 439-447.

[10] Foley, J. A., DeFries, R., Asner, G. P., Barford, C., Bonan, G., Carpenter, S. R., et al. (2005): Global consequences of land use. - Science 309(5734): 570.

[11] Fuhrer, J., Smith, P., Gobiet, A. (2014): Implications of climate change scenarios for agriculture in alpine regions - a case study in the Swiss Rhone catchment. - Science of the Total Environment 493(1232-1241). 
[12] Gao, N. N., Zhou, J. H., Zhang, X. L., Cai, W. T., Guan, T. Y., Jiang, L. H., Zheng, Y. R. (2017): Correlation between vegetation and environment at different levels in an arid, mountainous region of China. - Ecology and Evolution 7(14): 5482-5492.

[13] Gao, N. N, Li, F., Zeng, H., van Bilsen, D., De Jong, M. (2019): Can more accurate night-time remote sensing data simulate a more detailed population distribution? Sustainability 11: 4488.

[14] Gislason, P. O., Benediktsson, J. A., Sveinsson, J. R. (2006): Random Forests for land cover classification. - Pattern Recognition Letters 27(4): 294-300.

[15] Grimm, N. B., Chapin III, F. S., Bierwagen, B., Gonzalez, P., Groffman, P. M., Luo, Y., et al. (2013): The impacts of climate change on ecosystem structure and function. Frontiers in Ecology and The Environment 11(9): 474-482.

[16] Havstad, K. M., Brown, J. R., Estell, R., Elias, E., Rango, A., Steele, C. (2018): Vulnerabilities of Southwestern U.S. Rangeland-based animal agriculture to climate change. - Climate Change 148(3): 371-386.

[17] Hertel, T. W., Rosch, S. D. (2010): Climate change, agriculture, and poverty. - Applied Economic Perspectives and Policy 32(3): 355-385.

[18] Huete, A. (2016): Vegetation's responses to climate variability. - Nature 531(181).

[19] IPCC (2014): Climate Change 2014: Synthesis Report. - In: Pachauri, R., Meyer, L. (eds.) Contribution of Working Groups I, II and III to the Fifth Assessment Report of the Intergovernmental Panel on Climate Change. IPCC, Geneva.

[20] Jalut, G., Dedoubat, J. J., Fontugne, M., Otto, T. (2009): Holocene circum-Mediterranean vegetation changes: climate forcing and human impact. - Quaternary International 200(1): 4-18.

[21] Jiang, W., He, G., Long, T., Guo, H., Yin, R., Leng, W., et al. (2018): Potentiality of Using Luojia 1-01 Nighttime Light Imagery to Investigate Artificial Light Pollution. Sensors 18(9).

[22] Kolanowska, M., Kras, M., Lipińska, M. et al. (2017): Global warming not so harmful for all plants - response of holomycotrophic orchid species for the future climate change. Scientific Reports 7: 12704. https://doi.org/10.1038/s41598-017-13088-7.

[23] Lawler, J. J., Tear, T. H., Pyke, C., Shaw, M. R., Gonzalez, P., Kareiva, P., et al. (2010): Resource management in a changing and uncertain climate. - Frontiers in Ecology and The Environment 8(1): 35-43.

[24] Lepš, J., Šmilauer, P. (2003): Multivariate Analysis of Ecological Data Using CANOCO. - Cambridge University Press, Cambridge and New York.

[25] Lewis, S. L., Wheeler, C. E., Mitchard, E. T. A., Koch, A. (2019): Restoring natural forests is the best way to remove atmospheric carbon. - Nature 568: 25-28.

[26] Linderman, M. A., An, L., Bearer, S., He, G., Ouyang, Z., Liu, J. (2006): Interactive effects of natural and human disturbances on vegetation dynamics across landscapes. Ecological Applications 16(2): 452-463.

[27] Luo, K., Tao, F., Moiwo, J. P., Xiao, D. (2016): Attribution of hydrological change in Heihe River Basin to climate and land use change in the past three decades. - Scientific Reports 6(33704.

[28] Mantyka-pringle, C. S., Martin, T. G., Rhodes, J. R. (2012): Interactions between climate and habitat loss effects on biodiversity: a systematic review and meta-analysis. - Global Change Biology 18(4): 1239-1252.

[29] Montgomery, D. C., Peck, E. A., Vining, G. (2012): Introduction to Linear Regression Analysis. Fifth Ed. - John Wiley and Sons Ltd, Hoboken.

[30] Nemani, R. R., Keeling, C. D., Hashimoto, H., Jolly, W. M., Piper, S. C., Tucker, C. J., et al. (2003): Climate-driven increases in global terrestrial net primary production from 1982 to 1999 . - Science 300(5625): 1560. 
[31] Oliver, T. H., Morecroft, M. D. (2014): Interactions between climate change and land use change on biodiversity: attribution problems, risks, and opportunities. - Wiley Interdisciplinary Reviews: Climate Change 5(3): 317-335.

[32] Pielke Sr, R. A., Pitman, A., Niyogi, D., Mahmood, R., McAlpine, C., Hossain, F., et al. (2011): Land use/land cover changes and climate: modeling analysis and observational evidence. - Wiley Interdisciplinary Reviews: Climate Change 2(6): 828-850.

[33] Qin, C., Yang, B., Burchardt, I., Hu, X., Kang, X. (2010): Intensified pluvial conditions during the twentieth century in the inland Heihe River Basin in arid northwestern China over the past millennium. - Global and Planetary Change 72(3): 192-200.

[34] Serra, P., Pons, X., Saurí, D. (2008): Land-cover and land-use change in a Mediterranean landscape: a spatial analysis of driving forces integrating biophysical and human factors. - Applied Geography 28(3): 189-209.

[35] Shi, Y. (2003): Assessment of the Present Climate Change from Warm-Dry to Warm-Wet in Northwest China. - China Meteorological Press, Beijing.

[36] Sirami, C., Caplat, P., Popy, S., Clamens, A., Arlettaz, R., Jiguet, F., et al. (2017): Impacts of global change on species distributions: obstacles and solutions to integrate climate and land use. - Global Ecology and Biogeography 26(4): 385-394.

[37] ter Braak, C. J. F., Smilauer, P. (2002): CANOCO Reference Manual and CanoDraw for Windows User's Guide: Software for Canonical Community Ordination (version 4.5). www.canoco.com, Ithaca, NY.

[38] Titeux, N., Henle, K., Mihoub, J. B., Regos, A., Geijzendorffer, I. R., Cramer, W., et al. (2016): Biodiversity scenarios neglect future land-use changes. - Global Change Biology 22(7): 2505-2515.

[39] Vincens, A., Williamson, D., Thevenon, F., et al. (2003): Pollen-based vegetation changes in southern Tanzania during the last 4200 years: climate change and/or human impact. - Palaeogeography, Palaeoclimatology, Palaeoecology 198(3-4): 321-334.

[40] Wang, X., Bao, Y. (1999): Study on the methods of land use dynamic change research. Progress in Geography 18(1): 81-87.

[41] Watson, S. J., Luck, G. W., Spooner, P. G., Watson, D. M. (2014): Land-use change: incorporating the frequency, sequence, time span, and magnitude of changes into ecological research. - Frontiers in Ecology and The Environment 12(4): 241-249.

[42] Woodward, F. I., Lomas, M. R. (2004): Vegetation dynamics - simulating responses to climatic change. - Biological Reviews 79(3): 643-670.

[43] Wu, J. (2011): The effect of ecological management in the upper reaches of Heihe River. - Acta Ecologica Sinica 31(1): 1-7.

[44] Wu, J., Wang, Z., Li, W., Peng, J. (2013): Exploring factors affecting the relationship between light consumption and GDP based on DMSP/OLS nighttime satellite imagery. Remote Sensing of Environment 134(111-119).

[45] Wu, D., Zhao, X., Liang, S., Zhou, T., Huang, K., Tang, B., et al. (2015): Time-lag effects of global vegetation responses to climate change. - Global Change Biology 21(9): 3520-3531.

[46] Xu, Y., Ramanathan, V., Victor, D. G. (2018): Global warming will happen faster than we think. - Nature 564: 5.

[47] Zhang, Y., Gao, J., Liu, L., Wang, Z., Ding, M., Yang, X. (2013): NDVI-based vegetation changes and their responses to climate change from 1982 to 2011: A case study in the Koshi River Basin in the middle Himalayas. - Global and Planetary Change 108(139-148).

[48] Zhang, G., Wang, J., Jiang, Y., Zhou, P., Zhao, Y., Xu, Y. (2019): On-Orbit Geometric Calibration and Validation of Luojia 1-01 Night-Light Satellite. - Remote Sensing 11(3): 264. 